\title{
Lymphomatoid Papulosis in a Case of Atypical Secondary Syphilis
}

Xin Mu, BSc, Ian Mazzetti, MD FRCPC

\author{
About the Authors \\ Xin (Peter) Mu is a 1st-year IM resident at Memorial University, Newfoundland. \\ Dr. Ian Mazzetti is an intensivist and a member of the critical care team at the Windsor Regional Hospital. \\ Corresponding Author: ian.mazzetti@medportal.ca \\ Submitted: December 10, 2018. Accepted: January 18, 2019. Published: November 19, 2019. DOI: 10.22374/cjgim.v14i4.335
}

\begin{abstract}
Lymphomatoid papulosis is an indolent cutaneous lymphoproliferative disorder that presents as recurrent self-resolving papulonodular skin lesions. Currently, there are no known causes for lymphomatoid papulosis and definitive diagnosis is only made histologically. A 64-year-old man presented with a 6-week history of bilateral leg pains, low-grade fevers, and a widespread eruption of painless erythematic papules. Despite testing positive for syphilis serology, he lacked the typical clinical history for classic syphilis and therefore, skin biopsies were performed to confirm the diagnosis. Unexpectedly, the skin biopsies revealed lymphomatoid papulosis which resolved with antibiotic treatments for syphilis. Considering the synchronous resolution of the patient's syphilis infection and his cutaneous lesions, this is the first report of findings to suggest syphilis as a possible cause for lymphomatoid papulosis. Clinicians should appreciate the possibility of alternative diagnosis for cutaneous presentations in settings of confirmed syphilis infections.
\end{abstract}

\section{RESUME}

La papulose lympho-matoïde est un trouble lymphoprolifératif cutané indolent qui se présente sous la forme de lésions cutanées papulonodulaires auto-résolutives récurrentes. Actuellement, il n’y a pas de causes connues de la papulose lymphomatoïde et le diagnostic définitif n’est posé que sur le plan histologique. Un homme de 64 ans a présenté une histoire de 6 semaines de douleurs bilatérales aux jambes, de fièvres de bas grade et d'éruptions généralisées de papules érythémateuses indolores. Malgré un test sérologique positif pour la syphilis, il n’avait pas les antécédents cliniques typiques de la syphilis classique et des biopsies cutanées ont donc été effectuées pour confirmer le diagnostic. De façon inattendue, les biopsies cutanées ont révélé une papulose lymphomatoïde qui s'est résorbée grâce à des traitements antibiotiques contre la syphilis. Compte tenu de la résolution synchrone de linfection syphilitique du patient et de ses lésions cutanées, il s’agit du premier rapport de résultats suggérant que la syphilis est une cause possible de papulose lymphomatoïde. Les cliniciens devraient apprécier la possibilité d'un diagnostic alternatif pour les présentations cutanées dans les contextes d'infections syphilitiques confirmées. 


\section{Clinical Image}

A 64-year-old man was admitted to our institution with the progressive eruption of widespread rashes in the context of lancinating leg pains, recurrent fevers, and subacute development of asymptomatic lung opacities noted on recent CT chest. Examination revealed the presence of diffuse, non-pruritic, painless erythematic papules most predominantly concentrated in the chest, trunk, and lower limbs with no mucosal involvement (Figur 1). Following an initial infectious workup, the patient was found with positive Treponema pallidum serology and was started on penicillin G treatment. Due to inconsistencies in the patient's reported history, skin biopsies were obtained to confirm a diagnosis of secondary syphilis. Surprisingly, the biopsy results showed lymphomatoid papulosis (LyP); a rare form of primary cutaneous lymphoproliferative disorder. In consideration of recent pulmonary infiltrates and the absence of neurosyphilis, this is most likely an atypical presentation of secondary syphilis given the alternative cutaneous findings. ${ }^{1}$ Nevertheless, the patient saw a regression of his syphilis infection as well as LyP lesions with antibiotic treatment.

LyP is a chronic benign lymphoproliferative disorder that is characterized by recurrent eruptions of erythematic papulonodular lesions. ${ }^{2}$ The etiology of LyP is currently unknown and the genetic abnormalities behind LyP's immunophenotypic features appear to be complex with a high degree of variation among individual cases $^{2}$. Despite being long hailed as the "great imitator" due to its lengthened clinical course and variable presentations, syphilis is rarely considered as an etiology for the development of lymphoproliferative disorders. Connections between syphilis and lymphoproliferative disorders may have been overlooked by the urge to attribute abnormalities-clinically or histologicallyas manifestations of syphilis given its protean nature. Given the regression of LyP with syphilis treatment, syphilis should be considered as a risk factor for the development of chronic cutaneous lymphoproliferative disorders.

\section{Consent}

The patient provided informed consent for the use of photographs and other health information contained in this publication and is aware of the context of such use.

\section{Conflicts of Interests}

The authors have no actual or potential conflicts of interest to declare.

\section{Sources of Funding}

No funding was obtained for the publication of this article.

\section{References}

1. David G, Perpoint T, Boibieux A, et al. Secondary pulmonary syphilis: report of a likely case and literature review. Clin Infect Dis 2006;42:1-5.

2. De Souza A, El-Azhary RA, Camilleri MJ, et al. In search of prognostic indicators for lymphomatoid papulosis: A retrospective study of 123 patients. J Am Acad Dermatol 2012;66:928-37.
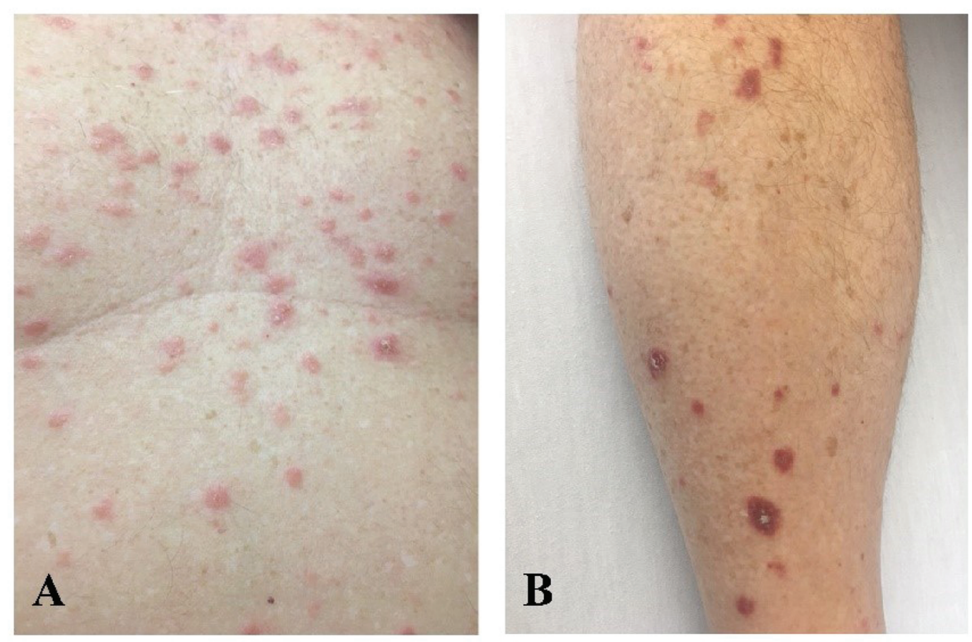

Figure 1. Clinical photographs of the patient's initial presentation: A. Diffuse erythematic papular lesions are most notably seen over the patient's chest. B. Lesions were also identified to a lesser extent on the patient's extremities. 